\title{
NOVOS PARADIGMAS, IDENTIDADES E CULTURAS: OLHARES, SIGNIFICADOS E REPRESENTAÇÕES EM ÁREAS DE DIREITOS
}

\author{
Rosely Aparecida Stefanes Pacheco*
}

\section{RESUMO}

Este artigo tem por objetivo discutir, dentro dos novos paradigmas do Direito, a temática das demandas indígenas e o lugar que ocupam no "campo" do direito, bem como verificar em que medida o discurso jurídico e a atuação do sistema jurídico podem ser instrumentos para a afirmação ou negação desses direitos. O que se propõe é submeter as "práticas jurídicas" a um exercício de reflexão crítica, no sentido da sociologia reflexiva de Pierre Bourdieu, colocando em "suspenso" as noções e os princípios que são tomados indistintamente como "naturais", no sentido de "afastarmo-nos" de qualquer possibilidade que possa servir como restrição de direitos. Isso porque o reconhecimento de uma cultura, no caso cultura indígena, determinou a obrigatoriedade, estabelecida tanto para o Estado quanto para a sociedade, de encarar o índio como cidadão, respeitando sua diversidade. Assim, propõem-se reflexões que visem a minimizar as questões que versam sobre os direitos desses povos, apontando a necessidade de um maior diálogo entre as várias áreas do conhecimento, em especial a Antropologia e o Direito.

Palavras-chaves: Diversidade étnica; Direito; Cultura.

[...] No entanto, vai-se em frente, pois o importante é se perder, porque ao perder descobre-se com mais profundidade os caminhos que levam aos destinos e, nessa busca, descobremse armadilhas que aniquilam porque matam, mas aprimoram porque ensinam a resistir [...].

(Oliveira, 2004).

* Mestre em História pela UFMS, Doutoranda em Direito, área de concentração: Direito Socioambiental, pela PUC-PR, Professora da Universidade Estadual de Mato Grosso do Sul - UEMS. Email: roselystefanes@bol.com.br e roselystefanes@ superig.com.br 
SUMÁRIO: INTRODUÇÃO; 1 A “INVENÇÃO" DO INDÍGENA BRASILEIRO; 2 BREVES CONSIDERAÇÕES SOBRE O DIREITO; 3 BREVES CONSIDERAÇÕES SOBRE OS AGENTES INVESTIDOS DO PODER-DIZER E DO SABER-FAZER O DIREITO; 4 CENÁRIOS EMERGENTES: NOVAS PERSPECTIVAS; 5 ANTROPOLOGIA E DIREITO: UM DIÁLOGO POSSÍVEL?; CONSIDERAÇÕES FINAIS; REFERÊNCIAS.

\section{INTRODUÇÃO}

Pensar criticamente, do ponto de vista da atual Ciência Jurídica, sobre a temática indígena é um grande desafio, em especial, porque a incorporação de alguns direitos não foi ou não é uma tarefa fácil, nem na perspectiva teórica nem na atuação prática. A afirmação dos direitos indígenas ocorre de inúmeras formas, dentre elas pode-se destacar: pela atuação das sociedades indígenas, entidades, instituições dentre outros atores sociais. No campo do direito positivo brasileiro, somente a partir da Constituição Federal de 1988, o direito à diversidade cultural indígena passou a ser reconhecido.

Nesse sentido, importa observar, na perspectiva jurídica, o locus a partir de onde se situa a fala ${ }^{1}$, com a intenção de se discutir, dentro dos novos paradigmas do direito, a temática dos direitos indígenas e de seu lugar ocupado no âmbito da Ciência Jurídica, bem como abordar em que medida a atuação do sistema jurídico e o seu discurso especializado podem ser instrumentos para a afirmação ou negação desses direitos. O que se propõe é submeter as "práticas jurídicas” a um exercício de reflexão crítica, no sentido da sociologia reflexiva de Pierre Bourdieu, colocando em "suspenso" as noções e os princípios que são tomados indistintamente como "naturais", no sentido de "afastá-los" de qualquer possibilidade que possa servir como restrição de direitos. Nessa perspectiva, faz-se oportuno a discussão sobre a

${ }^{1}$ BOURDIEU, Pierre. O poder simbólico. Trad. Fernando Tomaz. 6. ed. Rio de Janeiro: Bertrand Brasil, 2003. 
importância da transdisciplinariedade. Assim, do diálogo entre as várias disciplinas, em especial a Antropologia e o Direito, emergirão os novos argumentos a ser empregados, para minimizar as questões que versam sobre os direitos indígenas.

Para desenvolver a discussão sobre a temática indígena e os novos paradigmas do direito deve-se levar em consideração o que estava acontecendo no Brasil na década de 1980. Sabe-se que durante os anos 1980 viveu-se o fim do período militar, a volta das eleições, a volta à aparente normalidade democrática, enfim, desenhava-se o processo de reabertura democrática. Foi uma época de grandes movimentos sociais, e dentre esses movimentos destaca-se o indígena. Essa época foi marcada pela promulgação da Constituição de 1988.

Após 1988, fez-se necessário transformar as diretrizes das políticas públicas, partindo do reconhecimento oficial das múltiplas comunidades étnicas dentro do Brasil. Supera-se o vício histórico e burocrático de atendimento homogêneo indiferenciado a todo e qualquer cidadão do país. ${ }^{2}$

Desse processo, resultou uma nova definição para a sociedade brasileira que passa a ser designada como pluriétnica e multicultural, acolhendo uma proposta radicalmente diferenciada das Constituições anteriores, que pautadas pelo reconhecimento de um único credo e uma única língua oficial, instauravam uma idéia genérica de todos os povos. Conforme aponta Souza, "essa homogeneidade cultural foi pensada desde os valores de uma elite política e jurídica etnocêntrica”. ${ }^{3}$ Nesse sentido, pode-se explicar a grande dificuldade em se fazer efetivar uma nova legalidade, pois são estruturas multisseculares as que se apresentam nesse processo em transformação.

Essa transformação de paradigmas legais é vivida de maneira conflituosa e cheia de angústia pelos sujeitos que a experimentam. Entretanto, como se abordará adiante, a ciência antropológica já fornece ferramentas conceituais adequadas a

${ }^{2}$ SOUZA FILHO, Carlos Frederico Marés de. O renascer dos povos indígenas para o direito. 2. tir. Curitiba: Juruá, 1999, p. 187.

${ }^{3}$ Ibidem, p. 188. 


\section{NOVOS PARADIGMAS, IDENTIDADES E CULTURAS: OLHARES, SIGNIFICADOS E REPRESENTAÇÕES \\ EM ÁREAS DE DIREITOS}

encaminhar e acelerar esse processo de transição e transformação.

\section{A "INVENÇÃO" DO INDÍGENA BRASILEIRO}

Para desenvolver essa discussão a respeito dos novos paradigmas do direito e a inserção do indígena, na seara do Judiciário, precisa-se refletir sobre a forma como a identidade indígena é construída, bem como esses indígenas são pensadosrepresentados - assim também, rever os esquemas de pensamento jurídico dominante, cuja implicação primeira é de rever determinadas noções e princípios profundamente cristalizados e que se encontram "inculcados" nos "operadores do direito", a fim de reorganizá-los sistematicamente e hierarquicamente, no interior do sistema jurídico.

A recorrência de temas e problemáticas que versam sobre questões culturais parece ser uma marca que acompanha as ciências sociais e que, muitas vezes, se relaciona com o puro desconhecimento sobre a história de algum tópico ou sobre a riqueza dos intercâmbios inerentes a qualquer campo de discussão acadêmica. Como bem orienta Oliveira, nesses casos, o que se ganha em frescor, afinal novas perspectivas e olhares não enviesados podem ser uma fonte de estranhamento e vigor, perde-se em densidade e erudição. Porém, deve-se levar em consideração que o eterno retorno relaciona-se com a própria dinâmica da vida social, sempre cambiante, fluida. Assim, Oliveira, em seu artigo Amazônias: Sociedades Diversas Espacialidades Múltiplas, descreve:

[...] Por fim, os amazônidas conhecem os atalhos e as trilhas, nas quais são traçadas a caminhada que é a história. Muitas vezes não se sabe de onde vêm, mas sempre sabem para onde vão. Por instantes se perdem nos caminhos, na floresta, nos rios, nas estradas de terra batida, nas ruas, nos becos, nos igarapés, nas pontes, enfim, no espaço vivido do campo e das cidades que são espacialidades das vidas. No entanto, vai-se em frente, pois o importante é se perder, porque ao perder descobre-se com mais profundidade o caminho que levam aos destinos e, nessa busca, descobrem-se armadilhas que aniquilam porque matam, mas 
aprimoram porque ensinam a resistir. ${ }^{4}$

Este texto me fez repensar, ainda quando nos idos da década de 1980 me deparei, em um trabalho de campo com uma comunidade Guarani Kaiowá, no Estado de Mato Grosso do Sul, com a questão da identidade indígena, quando então pude começar a perceber que a noção de identidade indígena vai muito além dos nossos conceitos pré-concebidos de sociedade ocidental, ou seja, a identidade indígena passa a ser um construído diário, que não cabe em esquemas organizados em função dos métodos da cultura ocidental. Não obstante, vive-se, a partir das últimas décadas do século XX, o avanço de expressões poderosas de identidades coletivas que desafiam todo um sistema de singularidade cultural e de controle das pessoas sobre suas próprias vidas e ambientes. ${ }^{5}$

Os povos indígenas tornaram-se visíveis. Não é mais possível ignorá-los. E, nas suas demandas jurídico-políticas pela defesa de seus direitos, defendem antes de tudo sua identidade. ${ }^{6}$ Por esta razão, questionam o direito positivo da modernidade, sinalizando para uma apropriada mudança de sentido para alguns conceitos como: identidade, cultura, direitos, dentre outros. Assim, nas últimas duas décadas, os indígenas ressurgem na América Latina por forças próprias e de importantes aliados, e lentamente vão desnudando a história e reconstruindo um novo cenário.

Assim, o ponto central dos movimentos sociais indígenas, desde o final do século $\mathrm{XX}$, tem sido a exigência de reconhecimento e respeito a seus direitos como sociedades etnicamente diferenciadas - direitos políticos, territoriais, culturais, econômicos e sociais-; a afirmação de sua identidade étnica. Dessa forma, o processo identitário, muitas vezes se apresenta como processo legitimador para a inclusão dos

${ }^{4}$ OLIVEIRA José Aldemir de. Amazônias: sociedades diversas espacialidades múltiplas. Revista Hiléia de Direito Ambiental da Amazônia, Manaus, n. 2, p. 178, jan./jun. 2004.

5 STEFANES PACHECO, Rosely A. Mobilizações Guarani - Kaiowá Ñandeva e a (re)construção de territórios: (1978-2002) novas perspectivas para o direito indígena. Dourados, 2004, Dissertação de Mestrado em História, UFMS.

${ }^{6}$ LLANCAQUEO, Víctor Toledo. Pueblo Mapuche, derechos colectivos y territorio: desafíos para la sustentabilidad democrática. Santiago: LOM, 2006. 


\section{NOVOS PARADIGMAS, IDENTIDADES E CULTURAS: OLHARES, SIGNIFICADOS E REPRESENTAÇÕES EM ÁREAS DE DIREITOS}

direitos previstos nas Constituições e Acordos Internacionais ${ }^{7}$.

$\mathrm{Na}$ realidade, o que se pode observar é que, passo a passo, em diferentes lugares, mais comunidades estão reivindicando espaços e se fazendo presentes, dentro de um contexto maior, ou seja, global e, procurando se organizarem de acordo com suas especificidades. E, nesse contexto, as sociedades indígenas querem ser ouvidas a partir de um local determinado, como indígenas, participando de um processo histórico que, ao contrário do que já foi prognosticado, apresenta-se como um campo aberto de possibilidades. ${ }^{8}$

A questão cultural emerge, hoje, como dado fundamental para compreenderse os conceitos vivenciados na trajetória das sociedades indígenas. Até pouco tempo atrás, se acreditava saber com certeza do que se falava ao se nomear dicotomicamente o tradicional e o moderno, sem se levar em consideração que os povos indígenas renovam dia-a-dia seus modos de afirmação étnico, cultural e políticos. A sociedade não-indígena se tornara refém de um etnocentrismo dissimulado, que não a deixava compreender a dinâmica daquelas sociedades.

A problemática da relação entre o moderno e o tradicional tomou um novo direcionamento, embora já não se apresente na sua expressão dicotômica antiga. A noção de hibridismo, central na obra de Canclini, ${ }^{9}$ contempla uma nova forma de lidar com aquilo que outrora foi pensado como uma situação transitória. $\mathrm{O}$ que o autor traz de novo é que as identidades mudam e essa mudança passa eminentemente pelos processos de apropriação, ou seja, os indígenas ressignificam elementos e símbolos para seguirem traçando pontes entre suas memórias e utopias.

Para refletir sobre identidade e cultura é preciso deixar claro a imagem que o senso comum cria sobre os indígenas. $\mathrm{Na}$ realidade, tem-se uma imagem do índiohiper-real produzida por entidades civis contemporâneas, que operam com um índio

${ }^{7}$ Apesar da relevância, não abordar-se-á nesse trabalho os direitos indígenas conquistados nas Constituições latino-americanas e nos Acordos e Tratado Internacionais.

${ }^{8}$ STEFANES PACHECO, op. cit., 2004.

9 CANCLINI, Nestor Garcia. Culturas híbridas. Estratégias para entrar y salir de la modernidad. Grijalbo: México, 1990. 
perfeito, que guarda pouca relação com os índios reais.

Conforme orienta Hoffmann, ${ }^{10}$ esta visão recortada do problema indígena, isto é, sua apresentação descolada das diversas situações nacionais em que se encontram, parece adequar-se, por sua vez, ao modelo de gestão da questão indígena via projetos, adotado pelas agências tradicionalmente ligadas à temática do desenvolvimento, que sempre funcionaram sob este formato, seja em nome do combate à pobreza, seja em nome da promoção da modernização, ou, mais recentemente, da defesa dos direitos ambientais.

Com essa formação discursiva nacional-popular emergiu no imaginário “popular” e muitas vezes na história memorialística e na literatura, o ideal indígena pré-concebido persistindo em reconhecer o índio dentro de um conjunto de imagens estereotipadas sobre os índios baseadas em:

[...] habitantes da mata que vive em bandos nômades e anda nu, que possui uma tecnologia muito simples e tem uma religião própria (distinta do cristianismo). Os elementos fixos que compõem tal representação propiciam tanto a articulação de um discurso romântico, onde a natureza humana aflora com mais propriedade no homem primitivo, quanto na visão do selvagem como agressivo, cruel e repulsivo. ${ }^{11}$

Assim, conforme orienta Hoffmann, "[...] nesta imagem por recortes, o índio que emerge é um índio sem território específico, colocado fora das injunções das diversas realidades nacionais e dos problemas que elas nos desafiam a enfrentar". ${ }^{12}$

Diversos autores escreveram cada um à sua maneira, sobre a formação de um povo brasileiro que, tendo como ponto de partida a idéia de civilização, deveria ser constituído à sombra do elemento europeu, até se chegar ao ideal do branqueamento. Nessa seara, noções como assimilação, aculturação, branqueamento, cultura

${ }^{10}$ HOFFMANN, Maria Barroso. Do "Brasil sem índios" aos "índios sem Brasil": Algumas questões em torno da cooperação internacional junto aos povos indígenas no Brasil. Revista Antropológica, a. 9, v. 16, n. 2, p. 153-186, 2005.

${ }^{11}$ OLIVEIRA, João Pacheco de. Ensaios em antropologia histórica. Rio de Janeiro: Contra Capa, 1999.

${ }^{12}$ HOFFMANN, op. cit., p. 180. 


\section{NOVOS PARADIGMAS, IDENTIDADES E CULTURAS: OLHARES, SIGNIFICADOS E REPRESENTAÇÕES EM ÁREAS DE DIREITOS}

brasileira, caráter nacional - todas intimamente relacionadas com os processos migratórios, de ocupação territorial e de construção nacional - podem ser percebidas, de uma forma ou de outra, nos discursos da formação do povo brasileiro. Essas noções foram constantemente reorganizadas na forma de discursos que sintetiza grande parte dos pressupostos desenvolvidos pelos ideólogos da nação.

No caso do Brasil, a idéia de nação, entendida por intelectuais como, por exemplo, Oliveira Viana e Gilberto Freyre sustentaram por muito tempo o pilar fundamental de um discurso, que imaginava o Brasil, diante de constantes "correntes humanas" que por aqui transitaram direta ou indiretamente, e que isso consistiria num verdadeiro melting-pot tropical, erigido sob o "sangue" de brancos, índios e negros. Ensaiava-se um caráter tropical da formação da nacionalidade, ao mesmo tempo em que se apresentava a identidade como múltipla, porém única, homogeneizada, dando sentido a tudo aquilo que não pudesse ser definido por conceitos.

Importante destacar que os estados nacionais modernos não se organizam a partir de uma cultura nacional já existente. Ocorre o processo inverso. Os estados criam uma cultura comum nacional entre as diversas nacionalidades já existentes, para abranger os diferentes com base em um imaginário passado e futuro comum. Assim, a nação é pensada como uma comunidade imaginada, ${ }^{13}$ uma construção social, onde a língua nacional, a história nacional e o projeto nacional somente podem ser a língua, a história e o projeto dos grupos socialmente dominantes. Porém, este projeto não logrou êxito, pois as sociedades continuam reivindicando a diferença. Assim, na América Latina, a opção intercultural aparece como uma alternativa ético-política frente ao fracasso do assimilacionismo homogeneizante dos estados nacionais.

\footnotetext{
${ }^{13}$ ANDERSEN, Benedict . Imagined communities. Reflections on the origins and spread of
} 


\section{BREVES CONSIDERAÇÕES SOBRE O DIREITO}

Ao tratar de povos indígenas, o direito, tal qual está posto, não reflete as demandas e anseios desses povos. Porém, a dinâmica vivenciada por esses povos e grupos sociais na busca pelo direito de viver a diferença, joga luz no direito, pois esse se vê obrigado a reconhecer outras "práticas jurídicas", que se coadunam com outras formas de saber, mais localizados, situados nas experiências de cada grupo social. Contudo, não se pode ignorar que essa forma de "saber" sempre esteve sujeita aos sistemas formais.

Como bem observa Souza Filho, ${ }^{14}$ no tocante ao respeito aos direitos indígenas, o Estado contemporâneo e seu Direito sempre negaram a possibilidade de convivência, num mesmo território, de sistemas jurídicos diversos. O autor aponta que, ao mesmo tempo em que a construção do Direito brasileiro manteve como inexistente qualquer manifestação jurídica das sociedades indígenas, por elas foram sendo construídos institutos próprios para eles, cujo conjunto se convencionou chamar de direito indigenista.

Nesse sentido, cabe esclarecer que, normalmente, ao se tratar de Direito Indígena, refere-se ao direito que o Estado brasileiro reconhece aos índios - também tido como direito indigenista, e não ao direito dos índios propriamente dito, este já compreendido como o conjunto de normas próprias que regulam a conduta interna de cada sociedade indígena no Brasil. ${ }^{15}$

Carneiro $^{16}$ enfatiza que o direito ocidental ainda é predominantemente individualista, em que até os direitos coletivos são vistos como meios de satisfazer necessidades individuais, tanto que são sujeitos coletivos aqueles que representam

nationalism. Norfolk: Verson, 1986.

${ }^{14}$ SOUZA FILHO, Carlos Frederico Marés de. Textos clássicos sobre os direitos e os povos indígenas. Curitiba: Juruá/NDI, 1992.

${ }^{15}$ Idem, op. cit., 1999.

${ }^{16}$ CARNEIRO, Edilton Borges. Por uma hermenêutica constitucional e emancipatória. Hiléia: Revista de Direito Ambiental da Amazônia, Manaus, n. 3, 2005. 


\section{NOVOS PARADIGMAS, IDENTIDADES E CULTURAS: OLHARES, SIGNIFICADOS E REPRESENTAÇÕES EM ÁREAS DE DIREITOS}

interesses e vontades dos indivíduos que os formam. Os manuais já trazem um rol significativo de respostas prontas e rápidas, com um grau de abstração que exclui da apreciação do direito as necessidades complexas da convivência social.

Porém, a introdução do direito como regulador das relações sociais foi inicialmente o efeito de uma mudança de ordem jurídica. Mas, ao contrário daquilo que diriam os especialistas, isso não se pode explicar somente pela existência de novas normas jurídicas, nem pelo funcionamento das instituições jurídicas.

\section{Segundo Carneiro,}

A cultura jurídica brasileira está calcada em manuais, que por sua vez se resumem em comentários jurisprudenciais que não levam em conta os contextos nos quais os conflitos sociais ocorrem. Baseia-se a partir de raciocínios lógicos formais, que deixam à impressão irreal de que a realidade possa se subsumir a cultura do positivismo. O resultado é um direito que se aliena à realidade social, que tem a pretensão de que todos os problemas de uma sociedade cada vez mais complexa possam encontrar respostas e soluções nas normas abstratas existentes em seus manuais. ${ }^{17}$

\section{Luiz Streck destaca:}

A desconexão da ciência jurídica com a realidade social é patente quando, para explicar o estado de necessidade, os professores usam o caso de um naufrágio em alto-mar em que duas pessoas sobem em uma tábua, que podendo suportar apenas o peso de uma delas, gera uma disputa, e nesta um deles é morto. Está assim presente uma excludente de ilicitude em razão da necessidade do direito de proteção da própria vida. Um caso bastante surreal. ${ }^{18}$

E indaga por que motivo, ao invés de usar tal caso como exemplo, não se utiliza de um mais real como o caso de um menino pobre que adentra um supermercado para subtrair um pacote de bolacha a mando de sua mãe, que não tem o que comer em casa? Este é só um exemplo, porém os manuais jurídicos estão repletos de exemplos que não têm nenhum contato com a realidade, utilizando-se de

\footnotetext{
${ }^{17}$ Ibidem, p. 171,

${ }^{18}$ STRECK, Lenio Luiz. Hermenêutica jurídica e $(m)$ crise: uma exploração hermenêutica da construção do direito. Porto Alegre: Livraria do Advogado, 2004, p. 76.
} 
personagens como Cáio, Tício e Mévio dentre outros.

Segundo Silveira, ${ }^{19}$ como em nenhum outro campo do conhecimento, aprendese muito cedo nos cursos de Direito que há um mundo do direito, diferente do mundo real, que possui lógicas e categorias próprias de explicação da vida. Um mundo que, se auto-explicando, se basta.

Machado $^{20}$ ensina que, de maneira geral, a concepção positivista predominante nos cursos de Direito reduz o fenômeno jurídico a um conteúdo meramente legalista e formal, o que tem sacrificado em muito as idéias de justiça, eqüidade, igualdade, transformando-se num culto à lei, que juntamente com a crença da neutralidade do Judiciário, provocou o alheamento deste Poder ao que, na realidade, se passa com as sociedade(s), conferindo-lhe indiferença em relação aos conflitos e seu descomprometimento face às injustiças sociais. Isso levou o Poder Judiciário a cair nas armadilhas das instâncias dominantes, funcionando, com frequiência, como mecanismo de controle social, de produção e defesa de uma ordem jurídica mais consagradora de desigualdades do que de liberdades. ${ }^{21}$

Observa-se que em determinados momentos, o direito tal como tradicionalmente formulado e aplicado, tem servido mais como "obstáculo" às pretensões desses povos e grupos sociais, evidenciando assim o grau de disputas internas no campo jurídico, em que se coloca em questão a própria forma de dizer o direito.

Para Bourdieu, ${ }^{22}$ há um intenso movimento que tem a pretensão de criar uma homogeneização jurídica, a fim de que possa atender os propósitos de determinados grupos econômicos dominantes que atuam em toda parte.

${ }^{19}$ SILVEIRA, Domingos Sávio Dresch da. Novos personagens entram em cena...Afinal: a máquina judiciária gera mais violência?. In: FONSECA, Claudia; RABBEN Linda (orgs.). Antropologia, diversidade e direitos humanos. Porto Alegre: UFRGS, 2004.

${ }^{20}$ MACHADO, Marcello Lavenere. Justiça para o campo. In: CPT, Conflitos no Campo. Goiânia: Comissão Pastoral da Terra, 1996.

${ }^{21}$ Ibidem, p. 13.

${ }^{22}$ BOURDIEU, Pierre. Contrafogos 2: para um movimento social europeu. Trad. André Telles. Rio de Janeiro: Zahar, 2001, p. 107. 


\section{NOVOS PARADIGMAS, IDENTIDADES E CULTURAS: OLHARES, SIGNIFICADOS E REPRESENTAÇÕES EM ÁREAS DE DIREITOS}

Convém enfatizar que, para além das reivindicações dos povos e grupos sociais, se está diante de uma luta interna no campo jurídico, onde há um enfrentamento dos "operadores do direito" em dizer o direito.

\section{BREVES CONSIDERAÇÕES SOBRE OS AGENTES INVESTIDOS DO PODER-DIZER E DO SABER-FAZER O DIREITO}

Muitos "operadores" do direito fazem questão de enfatizar a existência de certa distância entre o mundo jurídico e suas formalidades e o restante dos segmentos sociais. Isso thes parece normal, afinal lhes ensinaram desde as primeiras lições, que existe um "mundo do direito", diferente do mundo dos fatos, no qual a vida, as pessoas $\mathrm{e}$ as coisas, tudo se reduz a normas, a teorias. ${ }^{23}$ Essa cuidadosa distância e diferenciação, não sem pretensão, do mundo real compõe a forma de ser da categoria profissional à qual se conferiu significativa parcela do poder do Estado - o Juiz. O Estado outorga a essas pessoas, após concluírem as formalidades escolares e serem aprovadas em concursos públicos, que passassem a decidir sobre a vida e a liberdade de outras pessoas.

De uma forma própria, os indígenas vêm apresentando ao Judiciário suas reivindicações e mostrado a situação em que vivem, pois, esta realidade em grande parte é desconhecida nos processos judiciais; até porque, abordado sob uma perspectiva interna, o processo judicial se constrói como universo fechado, dotado de lógica própria, a lógica jurídica, que, na maioria das vezes, não reflete as realidades sociais e políticas de que trata.

O contato com a situação evidencia aos "aplicadores da justiça" que suas concepções são muitas vezes estereotipadas, e noções como "aldeia", "tribos", "malocas", "aculturados", "que não são mais índios e sim paraguaios"- embora ultrapassadas, são representações operantes no discurso jurídico. 
A esse respeito, Bourdieu, ${ }^{24}$ ensina que a situação judicial funciona como lugar neutro, que opera uma verdadeira neutralização do que está em jogo, sendo que os agentes especializados, como terceiros, introduzem uma distância neutralizante a qual fica bem clara, principalmente no caso dos magistrados.

Conceitos como os mencionados acima, embora amplamente utilizados pelas diferentes disciplinas que compõem as ciências sociais, nem sempre possuem significados muito precisos, ou ainda, nem sempre são aplicados com critérios equivalentes.

Por ser freqüentemente usado, esse tipo de conceito acaba sendo desconsiderado como propriedade comum da ciência e, por isso mesmo, passa a ter uma definição quase "natural". E assim, contribui para legitimar determinadas maneiras de pensar e classificar que também se tornam formas naturais de ver e observar a realidade. Não obstante, levando em conta que como todo conceito é também objeto de uma construção, a análise requer, fundamentalmente, a sua desnaturalização ${ }^{25}$.

Carneiro alude para o fato de que a magistratura brasileira é treinada para se deparar com várias formas de ações, porém não para entender o contexto onde elas se desenvolvem, estando apegados a um formalismo procedimental e burocrático, que alegam ser impessoal, para garantia da certeza jurídica e da segurança do processo. E, que no "senso comum teórico", demonstram pouca preocupação com a melhor solução dos conflitos que se travam na sociedade, mas apenas se a decisão está nos parâmetros da juridicidade, tudo se resolvendo dentro da abstração jurídica, da neutralidade. ${ }^{26}$

Muitas vezes, o sistema judiciário está ancorado no mito do juiz como escravo da lei, ou, como queria Montesquieu, o juiz como sendo a boca que pronuncia as

${ }^{23}$ SILVEIRA, op. cit.

${ }^{24}$ BOURDIEU. O poder ..., op. cit.

${ }^{25}$ Nos termos de BOURDIEU, (O poder simbólico. Trad. Fernando Tomaz. 6. ed. Rio de Janeiro: Bertrand Brasil, 2003) diríamos "desconstruir o conceito".

${ }^{26}$ CARNEIRO, op. cit., p. 182. 


\section{NOVOS PARADIGMAS, IDENTIDADES E CULTURAS: OLHARES, SIGNIFICADOS E REPRESENTAÇÕES EM ÁREAS DE DIREITOS}

palavras da lei. Enfim, o mito fundante do positivismo jurídico, que afirma estar todo o direito reduzido à lei e as palavras da lei ter um único sentido possível.

No tocante aos conflitos territoriais os quais se tem acompanhado, apesar de terem mudado as normas jurídicas sobre o tema, não mudou, como regra geral, a concepção dos juízes que continuam decidindo situações do presente com idéias do passado. E de acordo com Silveira, ${ }^{27}$ é a forma social e culturalmente descontextualizada de decidir que faz com isso constituir-se uma forma de atuação geradora de violência.

Vieira, ${ }^{28}$ enfatiza que: A fundamentação de que há um rigor técnico, entendido este com sendo destituído de qualquer viés ideológico, portanto neutro, será fundamental para se estabelecer a imagem de neutralidade do Poder Judiciário, ao mesmo tempo em que abre brechas para a reprodução de um violento processo de controle social, pela sedimentação de estereótipos criminais ao movimento.

A autora prossegue explicitando que, "[...] essa busca de uma imparcialidade, essa defesa da neutralidade do juízo a quo, e, por conseguinte, do próprio Judiciário acabará por produzir contradições nas decisões, pois em nome da tecnicidade, da neutralidade apresentar-se-á, contraditoriamente, decisões pouco técnicas e longe de serem neutras". ${ }^{29}$

Afinal, como nos lembra Gizlene Neder, "[...] o discurso jurídico, ao erigir normas e constituir (i)legalidades, coloca-nos diante de um Direito que não é estático, nem mesmo 'positivo'. Ao normatizar, disciplinar e/ou confinar (e exterminar), apresenta-se como resultante de uma correlação de forças sociais e políticas em formações sociais historicamente estabelecidas". ${ }^{30}$

\footnotetext{
${ }^{27}$ SILVEIRA, op. cit.

${ }^{28}$ VIEIRA, Fernanda Maria da Costa. Presos em nome da lei? Estado penal e criminalização do MST. Dissertação de mestrado, Programa de Pós Graduação em Sociologia e Direito UFF, 2004, p. 84.

${ }^{29}$ Ibidem, loc. cit.

${ }^{30}$ NEDER, Gizlene. Discurso Jurídico e ordem burguesa no Brasil. Porto Alegre: Fabris,
} 1995, p. 98. 
A cultura jurídica pátria será calcada na noção de imparcialidade e neutralidade do juiz, que na relação jurisdicional representa o próprio Estado. Tal concepção será alicerçada por uma reificação ${ }^{31}$ da lei, estabelecida a partir da noção da existência de um direito natural, e não como o produto de relações sociais entre homens concretos numa determinada época.

Afinal, como lembra o professor Miguel Lanzellotti Baldez:

Com a ascensão da burguesia como classe política, transferem-se ao Estado, este novo sujeito absoluto e aparentemente neutro, a regulação e a administração das relações tipificadas na sociedade civil, bem como a remoção dos eventuais conflitos, reduzidos a interesses individualizados, dissimulando-se assim, com a elaboração ideológica do conceptualismo jurídico, o processo de luta de classes. A partir daí todos são iguais perante a lei, e as contradições se dão no concreto, sob a mediação do Estado, entre sujeito-operário e o sujeito-patrão (e não entre classe trabalhadora e a classe patronal), entre o sujeito-posseiro e o sujeito-grileiro, ou dono da terra (e não os sem-terra e os latifundiários), universal e abstratamente sujeitos (o operário, o patrão, o sem-terra, o latifundiário, todos sujeitos) e, por isso, conceptualmente, ou, em terminologia mais adequada, ideologicamente iguais perante a lei. Assim, é através da norma jurídica que são estabelecidos e controlados os limites da ação do operário na produção, como é através da norma jurídica que se protege a propriedade do latifundiário, e se impede o acesso do trabalhador à terra e à habitação. ${ }^{32}$

Essa concepção liberal-positivista sedimenta um processo de alienação dos conflitos/antagonismos que marcam o próprio conceito de Estado e da ordem legal vigente.

Portanto, o ordenamento jurídico é produto da vontade geral, gerador de um sujeito de direito, universalizado, por isso mesmo a ficção liberal de que todos são iguais perante a lei.

A reiteração desse ideário liberal-positivista de universalização do sujeito de

${ }^{31}$ Reificação aqui é entendida no sentido dado por Marx. Para ele, a objetividade das relações existentes entre os homens, o produto de suas ações, em dado momento perde sua característica objetiva de produto da ação/intervenção humana e assume características abstratas, em especial no capitalismo, tornando-se estranhas ao próprio homem, independentes destes, assumindo, assim, "a forma fantasmagórica de uma relação entre coisas (...) dotados de vida própria, figuras autônomas, que mantêm relações entre si e com os homens". (MARX, K. O capital. São Paulo: Nova Cultural, 1985, p. 71).

32 BALDEZ, Miguel Lanzellotti. Sobre o papel do direito na sociedade capitalista. Ocupações coletivas: direito insurgente. RJ: Centro de Defesa dos Direitos Humanos, 1989, p. 3. 


\section{NOVOS PARADIGMAS, IDENTIDADES E CULTURAS: OLHARES, SIGNIFICADOS E REPRESENTAÇÕES EM ÁREAS DE DIREITOS}

direito será um dos eixos adotados pelo Judiciário brasileiro como forma de controle das ações efetuadas pelos indígenas, isto porque o "sujeito de direito" aquele que, como tal, for reconhecido pela ordem jurídica, e a partir desse reconhecimento estará ele, de vez abstraído de suas características e fórmulas (facultas agendi) que lhe permitam o ordenamento jurídico (norma agendi), e obediente aos rituais (procedimentos) que assegurem a captação de seus atos e dos fatos de sua vida pelo corpo intransponível e limitado do Sujeito-Estado. Tal interpretação choca-se com o conceito que vem sendo sedimento em nosso Poder Judiciário. ${ }^{33}$

Quando se depara com os processos quer tramitam, sejam nas varas estaduais ou federais, que tratam sobre questões indígenas, os discursos analisados demonstram que atravessa esse exercício de controle efetuado pelo Judiciário, um "engessamento" do direito, uma construção ideológica de um direito formal, que expressa uma noção de "ordem social", hierarquizada e "imutável".

Conforme Carneiro, ${ }^{34}$ na atualidade, comprova-se que a atuação do judiciário brasileiro diante dos direitos indígenas consagrados na Constituição da República Federativa do Brasil de 1988, se em momentos foi o de garantir os avanços alcançados, em outros, utilizando-se do senso comum teórico, que lhes eximem da responsabilidade do resultado alcançado, foram feitas interpretações que distorcem tais direitos, consagrando um desrespeito ao texto constitucional.

Esta postura de parte do Judiciário nacional traz em suas decisões um conceito clássico de cidadania em que os índios, para igualarem-se aos cidadãos da cultura ocidental, que não lhes trariam ganhos, se tornariam emancipados, deixando de ser índios, tornando-se assim civilizados, tendo que se descaracterizar culturalmente.

Conforme aponta Ramos Filho, ${ }^{35}$ assim, aplicando apenas o que diz a lei, ou seja, fazendo uma interpretação literal da mesma, os magistrados eximem-se da

${ }^{33}$ VIEIRA, op. cit.

${ }^{34}$ CARNEIRO, op. cit.

${ }^{35}$ RAMOS FILHO, Wilson. Direito pós-moderno: caos criativo e neoliberalismo. In: MARQUES NETO, Agostinho Ramalho. Direito e neoliberalismo. Elementos para uma leitura interdisciplinar. Curitiba: Edibej, 1996. 
responsabilidade do resultado alcançado, mantendo dessa forma a predominância dos interesses das camadas dominantes. Tem-se observado enormes dificuldades jurídicas operacionais, sobretudo, em face da total impossibilidade de se "enquadrar" as situações vivenciadas aos modelos jurídicos preexistentes, os quais têm norteado e estruturado todo ordenamento jurídico; mesmo que esses modelos possam estar referidos de alguma forma as essas situações sociais, como é o caso dos dispositivos referidos no texto constitucional.

O renomado estudioso da história do direito Paolo Grossi aduz que, "o direito moderno está intimamente vinculado ao poder político como comando de um superior a um inferior - de cima para baixo -, visão imperativista que o identifica em uma norma, ou seja, em uma regra respeitável e autoritária (...), que tem um custo altíssimo". 36

É necessário considerar que especialização crescente no interior de várias disciplinas, produzida antes por lógicas particulares ao funcionamento dos establishments científicos do que pelas necessidades do saber, tem provocado efeitos perversos sobre o desenvolvimento das ciências sociais.

De acordo com Sigaud, ${ }^{37}$ presos na armadilha de uma divisão do trabalho intelectual, que é somente histórica, os praticantes da área das ciências sociais, mais especificamente terminam por crer na autonomia do domínio de estudo de sua escolha - a religião, a política, a cosmologia, para mencionar apenas alguns - em relação a outros domínios da práxis social, os quais não levam em conta ao produzirem interpretações. Assim, a autonomização conduz freqüentemente a tomar o objeto a partir do ponto de vista dos experts (juízes e advogados) e dos indivíduos e grupos interessados no direito. É isto que se observa, por exemplo, nos estudos que se limitam quer às normas ou às instituições jurídicas, quer ao reclamante, e não se preocupam em relacionar os fatos ligados ao direito com outros fatos sociais.

${ }^{36}$ GROSSI, Paolo. Mitologias jurídicas da modernidade. Trad. Arno Dal Ri Júnior. Florianópolis: Boiteux, 2004, p. 13.

${ }^{37}$ SIGAUD Lygia. Armadilhas da honra e do perdão: usos sociais do direito na mata pernambucana. Revista Mana, Rio de Janeiro, v. 10, n. 1, abr. 2004. 


\section{NOVOS PARADIGMAS, IDENTIDADES E CULTURAS: OLHARES, SIGNIFICADOS E REPRESENTAÇÕES EM ÁREAS DE DIREITOS}

Sigaud, ${ }^{38}$ afirma que, não raro, quando se trata de explicar, por exemplo, a ida à Justiça para a regulação de conflitos, o olhar é dirigido seja sobre os reclamantes sobre sua tomada de consciência das injustiças, sobre suas possibilidades de acesso às instituições jurídicas —, seja sobre o conteúdo das normas e a função dos experts (advogados e magistrados). Tudo se passa, então, como se não fosse necessário ir além do campo jurídico ${ }^{39}$, ou mesmo do direito, como se fosse possível compreender esta prática sem fazer a sociogênese dos conflitos, sem se interrogar sobre as propriedades sociais dos indivíduos envolvidos e a história de suas relações, sem, enfim, reinscrever os fatos relevantes do direito em quadros sociais mais amplos.

Como decorrência disso, passa a existir uma alienação da realidade, que conforme expõe Silveira, ${ }^{40}$ não encontra paralelo em outras áreas do conhecimento, já que não se fala em "mundo da medicina", "mundo da engenharia", fundamenta-se na ideologia jurídica que consagra o positivismo como forma de explicação do direito. Em suma, se temos o "nosso mundo", tudo deve se explicar pelas normas jurídicas, comandos estatais obrigatórios. Somos "ensinados" a reduzir todo o direito à lei. E quando a vida confronta-se com a lei... ora, mude-se a vida! ${ }^{41}$

Fachin afirma,

[...] o sistema jurídico, ao refletir o modelo que governa as relações econômicas e sociais, serve para marcar uma marginalização. É que atribuição de uma posição jurídica depende, pois, do ingresso da pessoa no universo de titularidade que o próprio sistema define. Desse modo, percebe-se claramente que o sistema jurídico pode ser antes de tudo, um sistema de exclusão. ${ }^{42}$

\footnotetext{
${ }^{38}$ Ibidem, loc. cit.
}

${ }^{39}$ Para Bourdieu ( $O$ poder ..., op. cit.), o campo jurídico é o lugar de concorrência pelo monopólio do direito dizer o direito, quer dizer a boa distribuição (nomos) ou a boa ordem, na qual se defrontam agentes investidos de competência ao mesmo social e técnica que consiste essencialmente na capacidade reconhecida de interpretar (de maneira mais ou menos livre ou autorizada) um corpus de textos que consagram a visão legitima, justa do mundo social.

${ }^{40}$ SILVEIRA, op. cit.

${ }^{41}$ Ibidem, p. 135.

${ }^{42}$ FACHIN, Luiz Edson. Da função pública ao espaço privado: aspectos da "privatização" da família no projeto do "Estado Mínimo". In: MARQUES NETO, Agostinho Ramalho (org.). Direito e neoliberalismo. Curitiba: Edibej, 1996, p. 147. 
Ainda, ao tratar sobre pessoas, direitos e exclusão, pondera que a exclusão se opera em relação a pessoas ou situações às quais a entrada na moldura das titularidades de direitos e deveres é negada. O autor ainda argumenta que, tal negativa, emergente da força preconceituosa e estigmatizante dos valores dominantes em cada época, alicerça-se num juízo depreciativo, historicamente atrasado e equivocado. ${ }^{43}$

Assim, pode-se considerar que o traço de exclusão das sociedades indígenas no Direito é uma construção que vem de longa data. Em muitos países, o fato do direito vir se apresentando como se fosse único, tem servido para justificar a sua total indiferença e o seu desprezo às noções de "local", de "realidade" e de "pluralidade".

Uma decorrência de tudo isso, conforme aponta Shiraishi, ${ }^{44}$ foi a criação de "ficções jurídicas", como a do "sujeito de direito", que se encontra destituído de suas raízes profundas, ou seja, não se trabalha arqueologicamente ${ }^{45}$ para recuperar essa noção de sujeito.

O mesmo autor enfatiza que a primazia da forma em detrimento do conteúdo tem levado os "sujeitos de direito" a uma espécie de "invisibilidade", destituindo esses sujeitos de quaisquer elementos que possam qualificá-los, perdendo as suas especificidades enquanto tal, como parte de determinado povo ou grupo social. Nesse sentido, as sociedades indígenas passaram e ainda passam por processos definidos pela sociedade não-indígena como sociedades invisíveis ou na melhor das hipóteses passíveis de homogeneização.

\footnotetext{
${ }^{43}$ Ibidem, loc. cit.
}

${ }^{44}$ SHIRAISHI NETO, Joaquim. Reflexão do direito das "comunidades tradicionais" a partir das Declarações e Convenções Internacionais. Hiléia: Revista de Direito Ambiental da Amazônia, Amazonas, a. 2, n. 3, 2006. 1975).

45 Nesse sentido ver FOUCAULT (A microfísica do poder. 5. ed. Rio de Janeiro: Graal, 


\section{CENÁRIOS EMERGENTES: NOVAS PERSPECTIVAS}

Certo é que, com as transformações sociais ocorridas nas últimas décadas, com "novos" sujeitos e "novos" cenários, impõem a construção de novas reflexões para a teoria jurídica em suas dimensões civil, pública e processual, capaz de contemplar o crescente aparecimento de novos-Direitos, uma vez que, as necessidades, os conflitos e os novos problemas colocados pela sociedade engendram também novas formas de direitos que desafiam e põem em dificuldade a dogmática jurídica tradicional, seus institutos formais e materiais e suas modalidades individualistas de tutela. $^{46}$

Segundo Shiraishi,

Tal movimento que se verifica no interior do direito, decorre de profundas transformações que está ocorrendo na órbita nacional e internacional, e ocorre pelo fato do direito não vir conseguindo responder de forma plena e satisfatória as demandas e reivindicações dos movimentos sociais, que afetam de forma direta e indireta a vida dos "povos" e "grupos sociais". Em outras palavras, o "desrespeito" às diferenças existentes entre os distintos sujeitos, materializado numa política de universalização dos direitos, vem provocando um aprofundamento dos problemas. ${ }^{47}$

Diante deste novo contexto, percebe-se que não existem mais juristas "senhores de si”; há um incômodo geral, principalmente no sentido de que é preciso construir um novo diálogo com outras disciplinas, pois, na realidade, tem-se uma série de eventos, regulamentos, políticas, costumes, crenças, sentimentos, símbolos, procedimentos e conceitos agrupados que não podem mais ser desconsiderados. ${ }^{48}$

E conforme orienta Silva,

O Direito enquanto Ciência e mais especificamente a Ciência do Direito Constitucional,

46 WOLKMER, Antonio Carlos (org.). Os "novos" direitos no Brasil: natureza e perspectivas: uma visão básica das novas conflituosidades jurídicas. São Paulo: Saraiva, 2003, p. 3.

${ }^{47}$ SHIRAISHI, op. cit., p. 180.

${ }^{48}$ STEFANES PACHECO, op. cit. 
devem ser compreendidas enquanto desentronizadas de uma unidade científica, mas como detentores de sinais diacríticos específicos em relação à Antropologia, História e Sociologia, dentro outras. Nestas ciências sociais, prepondera a responsabilidade para com a descrição realizada com fidedignidade sobre os grupos ou aspectos estudados em uma época ou sociedade nos quais muitas questões podem permanecer em aberto. Naquelas, de cunho jurídico, entretanto, indaga-se ao jurista, além das circunstâncias fáticas, sobre soluções pertinentes ao caso concreto. O Jurista está assim, às voltas com o interminável problema de fornecer respostas aos casos concretos. ${ }^{49}$

\section{ANTROPOLOGIA E DIREITO: UM DIÁLOGO POSSÍVEL?}

As reflexões acerca do sistema judiciário precisam ser trabalhadas, no sentido de sabê-lo como parte integrante de um campo político mais amplo com o qual se articula, tanto influenciando como sendo influenciado pelos processos sociais que nele ocorrem e não como uma esfera soberana, capaz de se situar acima de todos os demais poderes e etapas de decisão, isto é, como uma espécie de fonte de sabedoria do que seria justo e genuíno na garantia dos direitos sociais. Para tanto, os aportes teóricos de Bourdieu, ${ }^{50}$ Focault ${ }^{51}$ dentre outros, são de fundamental importância para a compreensão dessa temática.

Em uma tentativa de minimizar as questões que versam sobre os direitos indígenas e a demanda no sistema jurídico ocidental, entende-se que é necessário um diálogo entre as várias áreas do conhecimento, em especial a Antropologia e o Direito.

Esse diálogo tem me interessado sensivelmente, muito em função da pesquisa que desenvolvo sobre a temática das relações entre as leis e práticas sociais nas sociedades indígenas. Nela busco compreender tal relacionamento à luz da análise das situações em que a lei é usada e chamada a existir, e de como processos legais estão

49 SILVA, Dimas Salustiano da. Constituição democrática e diferença étnica no Brasil contemporâneo: um exercício constitucional-concretista face o problema do acesso à terra pelas comunidades negras remanescentes de quilombos. Curitiba, 1996, p. 156.

${ }^{50}$ BORDIEU (O poder simbólico. Trad. Fernando Tomaz. 6. ed. Rio de Janeiro: Bertrand Brasil, 2003; Razões práticas: sobre a teoria da ação. Campinas: Papirus, 1997).

${ }^{51}$ FOCAULT ("The subject and Power". Em Beyond Structuralism and Hermeneutics. Chicago: University of Chicago, 1983; A microfísica do poder. 5. ed. Rio de Janeiro: Graal, 1975). 


\section{NOVOS PARADIGMAS, IDENTIDADES E CULTURAS: OLHARES, SIGNIFICADOS E REPRESENTAÇÕES EM ÁREAS DE DIREITOS}

inseridos em relações sociais, ao mesmo tempo em que expressam tais relações. De forma geral, procuro identificar os processos de mobilizações territoriais indígenas, abordando a forma como os indígenas têm se relacionado com o Judiciário e como esses são vistos pela sociedade não-indígena.

Assim, ao analisar os processos jurídicos e extra-jurídicos procura-se demonstrar que a antropologia e o direito são bons desafios para se pensar sobre a temática indígena. Nesse sentido Sally Falk Moore,${ }^{52}$ dá um direcionamento sobre o campo da Antropologia do Direito nos últimos 50 anos, esta autora esclarece que se pode perceber três visões ou modos predominantes de se abordar o Direito: 1) o Direito como cultura; 2) o Direito como dominação; 3) o Direito como resolução de conflitos .

Diante dessas considerações de Moore ${ }^{53}$ pode-se etnograficamente, construir e/ou desconstruir cada uma destas percepções, pois a priori quando se inicia no trabalho do Direito, geralmente se é levado a visão do "Direito como dominação", ou seja, chega-se para assistir as audiências judiciais completamente apreensivo com todo o aparato institucional que é próprio do Direito e que contribui para sua tentativa de legitimação da autoridade jurídica: lugares específicos para cada ator ocupar de acordo com determinadas hierarquias institucionais (juiz em posição mais alta que os demais ocupantes da sala de audiências), símbolos "oficiais" dispostos no ambiente das audiências, tempos determinados e hierarquizados de fala para cada um dos participantes das audiências (juiz, promotor, defensor, técnicos, familiares e adolescente) e uma linguagem específica codificada que tenta produzir o efeito da neutralização e universalização das próprias normas jurídicas.

Em outros momentos, se é levado a entender o Direito como aquele que resolve os "conflitos" - numa visão normativa da realidade social. Porém, [descobrese] mais tarde, ao se considerar a amplitude e o alcance dessa Ciência e ao se analisar os fundamentos de sua própria formulação, descobre-se que na verdade nem nós nem o

\footnotetext{
${ }^{52}$ MOORE, Sally Falk. Certainties undone: fifty turbulent years of legal anthropology, 19491999. The Journal of the Royal Anthropological Institute 7, p. 95-116, 2001.

${ }^{53}$ Ibidem, loc. cit.
} 
Direito temos condições de responder a muitos dos mais variados conflitos.

Assim, surge o "Direito como cultura" que segue sendo um referencial válido - muito em função de assinalar a particularidade, a especificidade e a singularidade que envolve o "Direito como um saber local", conforme enfatiza Geertz. ${ }^{54}$

Porém, deve-se considerar que esse "direito como um saber local" tem sido constantemente questionado, muito em função do contexto histórico em que se encontra - em que não é possível diluir a importância das conexões entre o local e o global. As novas questões colocadas para e pelo Direito, como as leis de proteção aos direitos humanos, as demandas por reconhecimento cultural, as redes computadorizadas de informações, a mídia, dentre outros, vêm sendo vistas como fatores que recolocam o papel da cultura e o estudo no campo da Antropologia do Direito.

Estudos antropológicos poderão evidenciar várias questões quando se trata da temática envolvendo questões indígenas. Assim, nas disputas judiciais que envolvem os "elementos da cultura indígena", conforme afirma a jurisprudência, e os tratados e convenções internacionais ${ }^{55}$, deverão, de forma obrigatória, ser utilizada a pesquisa antropológica para amparar qualquer decisão. Neste sentido encontra-se o posicionamento de Bartolomé Clavero. ${ }^{56}$ Para o autor, os problemas envolvendo direitos indígenas, individuais e coletivos, no âmbito de uma cultura constitucionalista, só pode ser resolvido por meio de uma análise antropológica. E, assim destaca: Sigue siendo la antropología quien nos aclara estas cosas. ${ }^{57}$

Parte-se do princípio de que Direitos, afinal, são construções sociais, historicamente orientadas por necessidades humanas e ao antropólogo cabe desvendar aspectos dos processos sociais nos quais as "verdades" foram produzidas. Em resumo,

${ }^{54}$ GEERTZ, Clifford. Fatos e leis em uma perspectiva comparativa. O Saber Local. Petrópolis: Vozes, 1997.

${ }^{55}$ Nesse sentido ver a Convenção 169 da OIT (Organização Internacional do Trabalho) da qual o Brasil é signatário.

${ }^{56}$ CLAVERO, Bartolomé. Derecho Indígena y cultura constitucional en América. Madrid: Siglo XXI, 1994.

${ }^{57}$ Ibidem, p. 75. 


\section{NOVOS PARADIGMAS, IDENTIDADES E CULTURAS: OLHARES, SIGNIFICADOS E REPRESENTAÇÕES EM ÁREAS DE DIREITOS}

são as narrativas socialmente construídas que fornecem a "matéria-prima" para a reflexão antropológica.

Aspecto de grande relevância representa os trabalhos dos antropólogos junto à Justiça Federal e outros órgãos da União. Este trabalho tem sido fundamental para a superação de litígios com base em pareceres científicos. Oliveira ${ }^{58}$ enfatiza que o laudo pericial antropológico é considerado uma conquista das sociedades indígenas, pois se constitui em importante ferramenta a auxiliar e fundamentar as decisões judiciais.

Os estudos antropológicos, especialmente a perícia antropológica têm muito a contribuir para a ciência do direito, pois, ao antropólogo que se submete aos valores e regras do fazer científico, que demanda sólidos conhecimentos quanto aos princípios teóricos da disciplina que a embasa, cabe desvendar aspectos dos processos sociais no estudo de sociedades e povos não ocidentais, nos quais as "verdades" foram produzidas, viabilizado uma compreensão adequada, para além dos preconceitos do senso comum e dos interesses materiais comezinhos, de seus costumes e modos de vida. Segundo Luís Roberto Cardoso de Oliveira, ${ }^{59}$ o exercício da Antropologia, e em especial os trabalhos de perícia antropológica, demandam um comprometimento éticomoral profundo com os povos de cujos modos de vida nos tornamos íntimos ao longo de nosso investimento, seja para fins acadêmicos ou técnicos, em especial, no sentido de levar a sério o seu ponto de vista e suas tradições, tratar o tema e o grupo com honestidade, e assumir responsabilidades, para com o grupo, sobre o resultado de seu trabalho.

Diante dessas considerações, o que as novas demandas sociais trazem de novo, especialmente, nos tempos presentes, é uma afirmação positiva da diferença, da identidade. Este é o marco da diversidade, que traz à tona uma outra política de reconhecimento, em que a diferença e a especificidade assumem um espaço de afirmação, indo além do reconhecimento de uma frágil dignidade humana.

\footnotetext{
${ }^{58}$ OLIVEIRA. Ensaios ..., loc. cit.

${ }^{59}$ OLIVEIRA, Luís Roberto Cardoso de. Direitos culturalmente diferenciados, antropologia e ética. Disponível em: http://www.abant.org.br/index.php?page=3.4 Acesso em: 10 set. 2007.
} 


\section{CONSIDERAÇÕES FINAIS}

Sabe-se que a vida não nasce da lei. E se a vida não nasce da lei, é preciso descobrir com urgência, como dar vida à prática do direito Silveira. ${ }^{60}$ Como bem enfatiza o autor, é necessário assinalar que o processo de destruição contém a possibilidade da reconstrução, que ocorre a partir da resistência. Por isso, apesar de tudo, há resistências que vão além da noção de submissão, pois, conforme argumenta Albert: "[...] já é tempo de nos livrarmos de uma vez por todas da noção de resistência, sobretudo, pelo efeito de realidade que ela parece conferir a seu oposto, ou seja, a suposição de existir algo como uma submissão cultural". ${ }^{61}$

E nesse sentido, a discussão sobre o direito e os povos indígenas deve levar em conta a multiplicidade e heterogeneidade dos sujeitos com uma formação econômico-social e cultural produzida a partir da dinâmica histórica, territorial e cultural diferenciada.

Renan 1860, apud Rouland, ${ }^{62}$ assim afirmou: "Concebo para o futuro uma humanidade homogênea, na qual todos os riachos originais se fundirão num grande rio e na qual todas as lembranças das diversas origens estarão perdidas". Conforme aponta Roulan, enganar-se-ia considerando-o rapidamente, pois, "O futuro da humanidade situa-se exatamente na junção desses afluentes originais: não sem negações ela se opera diante de nós, e tomará séculos, sem dúvida. Mas se um universalismo autêntico dela nascer, ele se constituirá menos pela negação das diferenças do que pela remodelação delas, sem que a unidade signifique a uniformidade". O mesmo autor prossegue enfatizando que "Do mesmo modo é provável que se dilua a lembrança exata das origens longínquas. Mas duvidamos da

${ }^{60}$ SILVEIRA, op. cit.

${ }^{61}$ ALBERT, Bruce; RAMOS, Alcida (orgs.). Pacificando o branco. Cosmologia do contato no Norte Amazônico. São Paulo: UNESP, 2002, p. 15.

${ }^{62}$ ROULAND, Norbert. Direito das minorias e dos povos autóctones. Trad. Ane Lise Spaltemberg. Brasília: UnB, 2004, p. 607. 


\section{NOVOS PARADIGMAS, IDENTIDADES E CULTURAS: OLHARES, SIGNIFICADOS E REPRESENTAÇÕES EM ÁREAS DE DIREITOS}

homogeneidade do rio daí resultante. Garantiremos antes que aquele, curvado em meandros, cheio de imprevistos, será sempre tomado por agitações em que se recomporão identidades múltiplas".

As situações históricas vivenciadas pelos povos indígenas são produzidas socialmente, são produtos de uma cultura datada num determinado tempo e lugar. Concomitantemente, refletem as condições específicas do lugar e dos conflitos que não podem ser considerados exclusivamente do ponto de vista econômico e jurídico, pois têm dimensões que retratam o vivido de quem às constrói.

É preciso compreender a territorialidade que resulta das duras condições de vida, mas também da resistência, da força inquebrantável para a construção de uma nova vida que não é necessariamente melhor ou pior, mas é uma outra vida. ${ }^{63}$ Estas ações que se concretizam em transformações, mudanças de uma realidade, quase sempre são desconsideradas no universo do Judiciário.

Outro aspecto que deve ser enfatizado é que, não se pode partir da premissa de que o indígena é apenas vítima. Mesmo com todos os processos de aniquilação e exclusão, que tenta produzir novos e velhos pobres da terra, esses processos são responsáveis pela emergência de novos agentes produtores de um novo espaço e de um novo contexto. Para esses povos, o processo de produção do direito e do espaço tem perdas e ganhos. Há especificidades que decorrem do fato de os eventos que os atingem terem dinâmicas próprias, o que dificulta, senão impossibilita estabelecer generalizações para povos tão diferenciados, que devem ser considerados como sujeitos diversos com especificidades próprias.

A defesa da diferença, porém, não pode cair no particularismo. É preciso levar em consideração o que defende Harvey em Justice, Nature And Geography of Difference,${ }^{64}$ que não se deve perder de vista o processo social, em seu sentido mais amplo, e o que há de comum entre os vários segmentos sociais que lutam contra as diferentes formas de opressão. A realidade tem mostrado que, para além das

${ }^{63}$ OLIVEIRA. Amazônias ..., op. cit.

${ }^{64}$ HARVEY, David. Justice, nature and geography of difference. Oxford: Blackwell, 1996. 
diferenças, é possível a construção de alianças, a partir de interesses comuns, o que na prática tem resultado na formação de teias e redes, ${ }^{65}$ que cruzam espaços locais, nacionais e mundiais, como parece ser o caso das mobilizações indígenas.

Finalizando, entende-se que o campo do direito positivo pode ser alargado de sua condição de manutenção da ordem para a de garantia da justiça social. Conforme orienta Marques, ${ }^{66}$ A construção da justiça social hoje passa pelo reconhecimento $e$ pela institucionalização de conquistas políticas e sua transformação em direitos. E, esse movimento deve adotar como princípio a seguinte orientação:

\footnotetext{
Uma sociedade justa não é uma sociedade que adotou leis justas para sempre. Uma sociedade justa é uma sociedade onde a questão da justiça permanece constantemente aberta, ou seja, onde existe sempre a possibilidade socialmente efetiva de interrogação sobre a lei e sobre o fundamento da lei. ${ }^{67}$
}

\section{REFERÊNCIAS}

ALBERT, Bruce; RAMOS, Alcida (orgs.). Pacificando o branco. Cosmologia do contato no Norte Amazônico. São Paulo: UNESP, 2002.

ANDERSEN, Benedict . Imagined communities. Reflections on the origins and spread of nationalism. Norfolk: Verson, 1986.

BALDEZ, Miguel Lanzellotti. A terra no campo: a questão agrária. In: MOLINA, M. C.; SOUZA JÚNIOR, J. G. de; TOURINHO NETO, F. da C. Introdução crítica ao Direito Agrário. O direito achado na rua. Brasília/São Paulo: UnB/Imprensa Oficial, 2002. v. 3.

${ }^{65}$ CASTELLS, Manuel. O poder da identidade. São Paulo: Paz e Terra, 2001.

${ }^{66}$ MARQUES, Marta Inez Medeiros. Lugar do modo de vida tradicional na modernidade. In: OLIVEIRA, Ariovaldo Umbelino de; MARQUES, Marta Inez Medeiros. (orgs.). O campo no século XXI: território de vida, de luta e de construção da justiça social. São Paulo: Casa Amarela/Paz e Terra, 2004, p. 155.

${ }^{67}$ CASTORIADIS, Cornelius. Introdução: socialismo e sociedade autônoma. Socialismo ou barbárie. São Paulo: Brasiliense, 1983, p. 33. 


\section{NOVOS PARADIGMAS, IDENTIDADES E CULTURAS: OLHARES, SIGNIFICADOS E REPRESENTAÇÕES EM ÁREAS DE DIREITOS}

Sobre o papel do direito na sociedade capitalista. Ocupações coletivas: direito insurgente. RJ: Centro de Defesa dos Direitos Humanos, 1989.

BOURDIEU, Pierre. Contrafogos 2: para um movimento social europeu. Trad. André Telles. Rio de Janeiro: Zahar, 2001.

O poder simbólico. Trad. Fernando Tomaz. 6. ed. Rio de Janeiro: Bertrand Brasil, 2003.

Razões práticas: sobre a teoria da ação. Campinas: Papirus, 1997.

CANCLINI, Nestor Garcia. Culturas híbridas. Estratégias para entrar y salir de la modernidad. Grijalbo: México, 1990.

CARNEIRO, Edilton Borges. Por uma hermenêutica constitucional e emancipatória. Hiléia: Revista de Direito Ambiental da Amazônia, Manaus, n. 3, 2005.

CASTELLS, Manuel. O poder da identidade. São Paulo: Paz e Terra, 2001.

CASTORIADIS, Cornelius. Introdução: socialismo e sociedade autônoma. Socialismo ou barbárie. São Paulo: Brasiliense, 1983.

CHARTIER, Roger. A história cultural: entre práticas e representações. Lisboa/Rio de Janeiro: Difel/Bertrand Brasil, 1988.

CLAVERO, Bartolomé. Derecho Indígena y cultura constitucional en América. Madrid: Siglo XXI, 1994.

DE LA TORRE, Jesus Antonio. El derecho que nasce del pueblo. México: Porrúa, 2005.

Pluralismo Jurídico enquanto Fundamentação para a autonomia indígena. In: WOLKMER, Antônio Carlos (org.) Direitos humanos e filosofia jurídica na América Latina. Rio de Janeiro: Lumen Juris, 2004.

FACHIN, Luiz Edson. Da função pública ao espaço privado: aspectos da "privatização" da família no projeto do "Estado Mínimo". In: MARQUES NETO, Agostinho Ramalho (org.). Direito e neoliberalismo. Curitiba: Edibej, 1996.

FAJARDO, Raquel Yrigoyen. Vislumbrando un horizonte pluralista: rupturas y retos epistemológicos y políticos. In: CASTRO, Milka. Los desafios de la interculturalidad: identidad, política y derecho. Santiago: LOM, 2004.

. Retos para construir una juridicidad pluralista. In: ENCUENTRO DE LA SECCIÓN PERUANA DE ANTROPOLOGIA JURÍDICA. Lima, PUC, 2001.

FOCAULT, Michel. "The subject and Power". Em Beyond Structuralism and Hermeneutics. Chicago: University of Chicago, 1983. 
A microfísica do poder. 5. ed. Rio de Janeiro: Graal, 1975.

GEERTZ, Clifford. Fatos e leis em uma perspectiva comparativa. O Saber Local. Petrópolis: Vozes, 1997.

GROSSI, Paolo. Mitologias jurídicas da modernidade. Trad. Arno Dal Ri Júnior. Florianópolis: Boiteux, 2004.

HARVEY, David. Justice, nature and geography of difference. Oxford: Blackwell, 1996.

HOFFMANN, Maria Barroso. Do "Brasil sem índios" aos "índios sem Brasil": Algumas questões em torno da cooperação internacional junto aos povos indígenas no Brasil. Revista Antropológica, a. 9, v. 16, n. 2, p. 153-186, 2005.

LEITÃO, Ana Valéria Nascimento Araújo. Direitos culturais dos povos indígenasaspectos do seu reconhecimento. In: Os direitos indígenas e a Constituição. Porto Alegre: Fabris, 1993.

LIMA, Antonio Carlos de Souza. Questões para uma política indigenista: etnodesenvolvimento e políticas públicas. In: ; HOFFMANN, Maria Barroso (orgs.). Etnodesenvolvimento e políticas públicas:bases para uma nova política indigenista. Rio de Janeiro: Contra Capa, 2002.

LLANCAQUEO, Víctor Toledo. Pueblo Mapuche, derechos colectivos y territorio:desafios para la sustentabilidad democrática. Santiago: LOM, 2006.

MACHADO, Marcello Lavenere. Justiça para o campo. In: CPT, Conflitos no Campo. Goiânia: Comissão Pastoral da Terra, 1996.

MARQUES, Marta Inez Medeiros. Lugar do modo de vida tradicional na modernidade. In: OLIVEIRA, Ariovaldo Umbelino de; MARQUES, Marta Inez Medeiros. (orgs.). O campo no século XXI: território de vida, de luta e de construção da justiça social. São Paulo: Casa Amarela/Paz e Terra, 2004.

MARX, K. O capital. São Paulo: Nova Cultural, 1985. (Col. Os Economistas)

MOORE, Sally Falk. Certainties undone: fifty turbulent years of legal anthropology, 1949-1999. The Journal of the Royal Anthropological Institute 7, p. 95-116, 2001.

NEDER, Gizlene. Discurso Jurídico e ordem burguesa no Brasil. Porto Alegre: Fabris, 1995.

NEVES, Lino João de Oliveira. Olhos mágicos dos Sul (do Sul): lutas contrahegemônicas dos povos indígenas no Brasil. In: SANTOS, Boaventura de Souza. (org.). Reconhecer para libertar: os caminhos do cosmopolitismo multicultural. Rio de Janeiro: Civilização Brasileira, 2003. 


\section{NOVOS PARADIGMAS, IDENTIDADES E CULTURAS: OLHARES, SIGNIFICADOS E REPRESENTAÇÕES EM ÁREAS DE DIREITOS}

OLIVEIRA José Aldemir de. Amazônias: sociedades diversas espacialidades múltiplas. Revista Hiléia de Direito Ambiental da Amazônia, Manaus, n. 2, jan./jun. 2004.

OLIVEIRA, João Pacheco de. Ensaios em antropologia histórica. Rio de Janeiro: Contra Capa, 1999.

OLIVEIRA, Luís Roberto Cardoso de. Direitos culturalmente diferenciados, antropologia e ética. Disponível em: http://www.abant.org.br/index.php?page=3.4 Acesso em: 10 set. 2007.

RAMOS FILHO, Wilson. Direito pós-moderno: caos criativo e neoliberalismo. In: MARQUES NETO, Agostinho Ramalho. Direito e neoliberalismo. Elementos para uma leitura interdisciplinar. Curitiba: Edibej, 1996.

ROULAND, Norbert. Direito das minorias e dos povos autóctones. Trad. Ane Lise Spaltemberg. Brasília: UnB, 2004.

SHIRAISHI NETO, Joaquim. Reflexão do direito das "comunidades tradicionais" a partir das Declarações e Convenções Internacionais. Hiléia: Revista de Direito Ambiental da Amazônia, Amazonas, a. 2, n. 3, 2006.

Reflexão do direito das "comunidades tradicionais" a partir das declarações e convenções internacionais. Hiléia - Revista de Direito Ambiental da Amazônia, a. 2, n. $3,2004$.

SIGAUD Lygia. Armadilhas da honra e do perdão: usos sociais do direito na mata pernambucana. Revista Mana, Rio de Janeiro, v. 10, n. 1, abr. 2004.

SILVA, Dimas Salustiano da. Constituição democrática e diferença étnica no Brasil contemporâneo: um exercício constitucional-concretista face o problema do acesso à terra pelas comunidades negras remanescentes de quilombos. Curitiba, 1996, Programa de Pós Graduação Doutorado em Direito.

SILVEIRA, Domingos Sávio Dresch da. Novos personagens entram em cena...Afinal: a máquina judiciária gera mais violência?. In: FONSECA, Claudia; RABBEN Linda (orgs.). Antropologia, diversidade e direitos humanos. Porto Alegre: UFRGS, 2004.

SOUZA FILHO, Carlos Frederico Marés de. $O$ renascer dos povos indígenas para o direito. 2. tir. Curitiba: Juruá, 1999.

1992.

Textos clássicos sobre os direitos e os povos indígenas. Curitiba: Juruá/NDI,

STEFANES PACHECO, Rosely A. Direito indígena: da pluralidade cultural a pluralidade jurídica. Revista Tellus, Núcleos de Estudos e Pesquisas das Populações Indígenas- NEPPI, Campo Grande, a. 6, n. 11, out. 2006. 
. Mobilizações Guarani - Kaiowá Ñandeva e a (re)construção de territórios: (1978-2002) novas perspectivas para o direito indígena. Dourados, 2004, Dissertação de Mestrado em História, UFMS.

STRECK, Lenio Luiz. Hermenêutica jurídica e(m) crise: uma exploração hermenêutica da construção do direito. Porto Alegre: Livraria do Advogado, 2004.

VIEIRA, Fernanda Maria da Costa. Presos em nome da lei? Estado penal e criminalização do MST. Dissertação de mestrado, Programa de Pós Graduação em Sociologia e Direito UFF, 2004.

WOLKMER, Antonio Carlos (org.). Os “novos” direitos no Brasil: natureza e perspectivas: uma visão básica das novas conflituosidades jurídicas. São Paulo: Saraiva, 2003.

\begin{abstract}
This article has for objective to inside argue of the new paradigms of the Right the thematic one of the indian demands and the place that occupies in the "field" of the right, as well as verifying where measured the legal speech and the performance of the legal system can be instrument for the affirmation or negation of these rights. What it is considered is to submit the "practical legal ones" to an exercise of critical reflection, in the direction of the reflexiva sociology of Pierre Bourdieu, , placing in "suspended" the slight knowledge and the principles that are taken as "natural indistinctly", in the direction "to move away itself" from any possibility that can serve as restriction of rights. This because the recognition of a culture, in the case indian culture, determined the obligatoriness, established in such a way for the State how much for the society, to face the indian as citizen, respecting its diversity. Thus, reflections are considered that they aim at to minimize the questions that turn on the rights of these peoples, pointing the necessity of a bigger dialogue enters the some areas of the knowledge, in special the Anthropology and the Right.
\end{abstract}

Words Keys: Ethnic diversity; Right; Culture. 